\title{
Salinomycin induces endoplasmic reticulum stress-mediated autophagy and apoptosis through generation of reactive oxygen species in human glioma U87MG cells
}

\author{
SUN-NYOUNG YU ${ }^{1,2}$, SANG-HUN KIM ${ }^{1}$, KWANG-YOUN KIM ${ }^{3}$, JAE-HOON JI ${ }^{4}$, \\ YOUNG-KYO SEO ${ }^{5}$, HAK SUN YU ${ }^{2,6}$ and SOON-CHEOL AHN ${ }^{1,2}$ \\ ${ }^{1}$ Department of Microbiology and Immunology, Pusan National University School of Medicine, Yangsan 50612; \\ ${ }^{2}$ Immunoregulatory Therapeutics Group in Brain Busan 21 Project, Pusan National University, Yangsan 50612; \\ ${ }^{3}$ Department of Herbal Formula, Medical Research Center (MRC-GHF), College of Oriental Medicine, \\ Daegu Haany University, Gyeongsan 38610; ${ }^{4}$ Genome Instability Research, Ajou University School of Medicine, \\ Suwon 16502; ${ }^{5}$ School of Life Sciences, Ulsan National Institute of Science and Technology, Ulsan 44919; \\ ${ }^{6}$ Department of Parasitology, Pusan National University School of Medicine, Yangsan 50612, Republic of Korea
}

Received November 7, 2016; Accepted December 27, 2016

DOI: $10.3892 /$ or.2017.5615

\begin{abstract}
Salinomycin is a polyether ionophore antibiotic that has recently been shown to induce cell apoptosis in human cancer cells displaying multiple mechanisms of drug resistance. In the present study, we explored the impact of salinomycin on the apoptosis and autophagy as well as the correlation between those effects and endoplasmic reticulum (ER) stress molecular mechanisms in human glioma U87MG cells. Apoptosis, autophagy and reactive oxygen species (ROS) were analyzed using flow cytometry. In addition, expression levels of apoptosis-, autophagy- and ER stress-related proteins were determined by western blotting. The results showed that salinomycin induced apoptosis, ER stress and autophagy in glioma cancer cell lines. In addition, salinomycin also induced ROS generation, and the ROS scavenger N-acetyl-L-cysteine was found to inhibit the salinomycin-induced apoptosis, ER stress and autophagy. The inhibition of ER stress with 4-phenylbutyric acid depressed salinomycin-induced apoptosis and autophagy. Salinomycin increased the expression of autophagy marker protein, LC3B, and accumulation of acidic vesicular organelles. Furthermore, pre-treatment with the autophagy inhibitor 3-methyladenine showed potential in increasing the apoptosis rate induced by salinomycin in the U87MG cells. Taken together, these results revealed that salinomycin induced apoptosis and autophagy via ER stress mediated by ROS, suggesting that ER stress by salinomycin plays a dual function in both promoting and suppressing cell death.
\end{abstract}

Correspondence to: Professor Soon-Cheol Ahn, Department of Microbiology and Immunology, Pusan National University School of Medicine, Yangsan, Gyeongsangnam-do 50612, Republic of Korea E-mail: ahnsc@pusan.ac.kr

Key words: apoptosis, autophagy, ER stress, salinomycin, U87MG cells

\section{Introduction}

Salinomycin, a carboxylic polyether ionopore isolated from Streptomyces albus, has been used extensively as an agricultural antibiotic to prevent coccidiosis in poultry. Recent studies have shown that salinomycin displays potent antitumor activities in different types of cancer cells, including colorectal cancer (1), hepatocellular carcinoma (2), endometrial (3) and prostate cancer (4), and osteosacoma cells (5). However, there are few studies on its effect on glioma cancer cells (6). Gliomas are the most primary prevalent and aggressive form of intracranial tumors affecting adults $40-60$ years of age $(7,8)$. Despite multidisciplinary treatments including surgery, chemotherapy and radiotherapy, it has a poor prognosis with a median survival of less than 15 months (9). Moreover, although chemotherapy has been used most extensively in glioma cancer patients and has contributed to substantial improvement in the survival rate, it was ultimately confirmed to be ineffective owing to severe toxicity, the incapacity of many drugs to cross the blood-brain barrier and high levels of drug resistance (10).

Reactive oxygen species (ROS) are normal byproducts of numerous cellular processes, such as mitochondrial metabolism and protein folding. The balance of redox homeostasis is regulated by two major cellular antioxidant systems, including the glutathione and the thioredoxin system, which plays a crucial role in cellular viability and function $(11,12)$. In contrast, overproduction of ROS disrupts the intracellular redox balance and exerts oxidative stress on cancer cells that can ultimately cause cell senescence or death (13). ROS play an important role in the determination of cell death or survival (14). Recent studies have shown that endoplasmic reticulum (ER) stress has a dual function; either promotion of cell survival or triggering of cell death depending on an imbalance between ER protein folding load and capacity (15). ER has two key roles in eukaryotic cells, namely protein processing and intracellular calcium storage. ER stress is triggered under various physiological and pathological conditions, such as exposure to chemotherapeutic 
agents and accumulation of unfolded proteins (16). However, accumulation of misfolded proteins in the ER lumen causes ER stress to initiate the expression of chaperones and proteins and several folding enzymes. While moderate ER stress promotes cell survival and enhances chemotherapeutic resistance, severe stress leads to cell apoptosis (17). Moreover, unfolded protein response signaling may activate autophagy to clear the accumulated misfolded proteins from the ER lumen (18). Autophagy is an intercellular process for catabolic degradation to maintain cellular homeostasis during metabolic stress and it is involved in the formation of autophagosomes, which are further fused with lysosomes to form acidic vesicular organelles including autolysosomes. Since cancer cells often exhibit defective autophagic capacities, autophagic cell death is considered as a tumor suppressor. However, emerging evidence indicates that autophagy is not only a death pathway, but also a survival pathway exploited by cancer cells to endure metabolic stress (19). In addition, the inhibition of autophagy leads to apoptotic cell death as a result of the failure to adapt to stress. Therefore, autophagy inhibitors are also considered as an attractive strategy to enhance the sensitivity of cancer cells to anticancer drugs by manipulating the autophagic process (20).

In the present study, we observed that salinomycin induced autophagy and apoptosis in glioma U87MG cells. These processes were regulated through a dual function of ER stress: cell survival and cell death. In addition, ER stress responses were regulated by upstream ROS. In addition, pharmacological inhibition of autophagy enhanced salinomycin-mediated apoptosis, suggesting a new approach for glioma cancer therapy.

\section{Materials and methods}

Reagents and antibodies. 3-(4,5-Dimethylthiazol-2-yl)-2,5diphenyltertrazolium bromide (MTT), N-acetyl-L-cysteine (NAC), 3-methyladenine (3-MA), 4-phenylbutyric acid (4-PBA), 6-diamidino-2-phenylindole dihydrochloride (DAPI), 2'-7'-dichlorodihydrofluoresceine diacetate (DCFH-DA) and salinomycin were purchased from Sigma Chemical Co. (St. Louis, MO, USA). Annexin V-FITC apoptosis detection kit was purchased from BD Biosciences (San Jose, CA, USA). The WesternBright ECL kit was purchased from Advansta, Inc. (Menlo Park, CA, USA). Antibodies against Bip, procaspase-3, CHOP, Ire $\alpha$, LC3B and $\beta$-actin were purchased from Cell Signaling Technology (Beverly, MA, USA).

Cell lines and culture. Human glioma U87MG cells were obtained from the American Type Culture Collection (ATCC; Manassas, VA, USA). The U87MG cells were cultured in Dulbecco's modified Eagle's medium minimal (DMEM) supplemented with $10 \%$ fetal bovine serum (FBS) and $100 \mathrm{U} / \mathrm{ml}$ of penicillin and $100 \mu \mathrm{g} / \mathrm{ml}$ of streptomycin (all from WelGENE Inc., Daegu, Korea). Cells were cultured in a humidified atmosphere with $5 \% \mathrm{CO}_{2}$ at $37^{\circ} \mathrm{C}$.

Cell viability. Cell viability was measured using the MTT assay. Cells were seeded and treated with various concentrations of salinomycin for 24 or $48 \mathrm{~h}$. After salinomycin treatment, $1 \mathrm{mg} / \mathrm{ml}$ of MTT was added to each well and incubated for $3 \mathrm{~h}$ at $37^{\circ} \mathrm{C}$. Then, the medium was removed and MTT-formazan complex was dissolved in dimethyl sulfoxide. Absorbance was observed at $570 \mathrm{~nm}$ using the $\mathrm{VERSA}_{\max }$ microplate reader (Molecular Devices, Toronto, Canada). Cell viability was determined as the relative percentage of treated cells to the untreated cells by comparing optical densities.

Morphological changes. Nuclear morphological changes were measured by fluorescence microscopy. Cells were incubated in the absence or presence of salinomycin for $48 \mathrm{~h}$. The cells were fixed with $4 \%$ paraformaldehyde, and then stained with $1 \mathrm{mg} / \mathrm{ml}$ of DAPI solution for $10 \mathrm{~min}$. After washing, the cells were observed under fluorescence microscopy (Axio Imager; Zeiss, Jena, Germany).

Annexin V/PI double staining. Apoptotic cells were assessed by an Annexin V-FITC staining kit. Briefly, the U87MG cells were treated with various concentrations of salinomycin for $48 \mathrm{~h}$ and then were washed with phosphate-buffered saline (PBS). Collected cells were mixed in $100 \mu \mathrm{l}$ of $1 \mathrm{X}$ Annexin binding buffer. After Annexin V/PI double staining for 20 min, cells were analyzed by flow cytometry (FACSCalibur; Becton-Dickinson, Franklin Lakes, NJ, USA). The apoptotic cells were calculated using Cell Quest Pro software on $\mathrm{Mac}^{\circledR}$ OS 9 (Becton-Dickinson).

ROS generation. ROS were measured using DCFH-DA fluorescent dye. The cells were cultured in a 6-well plate at a density of $2.5 \times 10^{4} /$ well. After treatment with salinomycin for 24 or $48 \mathrm{~h}$, the cells were incubated with $10 \mu \mathrm{M}$ of DCFH-DA at $37^{\circ} \mathrm{C}$ for $30 \mathrm{~min}$. After the cells were harvested, the intensity of fluorescence was measured using flow cytometry and calculated using Cell Quest Pro software on Mac ${ }^{\circledR}$ OS 9.

Acidic vesicular organelle detection. To detect acidic vesicular organelles, the cells were cultured in a 6-well plate at a density of $2.5 \times 10^{4} /$ well. After treatment with $4 \mu \mathrm{M}$ of salinomycin for $48 \mathrm{~h}$, cells were stained with $1 \mu \mathrm{M}$ acridine orange for $30 \mathrm{~min}$. The stained cells were analyzed by flow cytometry and calculated using Cell Quest Pro software on Mac ${ }^{\circledR}$ OS 9.

Western blotting. Whole extracts were prepared by incubating the cells in lysis buffer [150 mM NaCl, $10 \mathrm{mM}$ Tris (pH 7.4), 5 mM EDTA (pH 8.0), 1\% Triton X-100, 1 mM PMSF, $20 \mu \mathrm{g} / \mathrm{ml}$ aprotinin, $50 \mu \mathrm{g} / \mathrm{ml}$ leupeptin, $1 \mathrm{mM}$ benzidine, $1 \mathrm{mg} / \mathrm{ml}$ pepstatin, $8 \mathrm{mM}$ sodium pyrophosphate and $20 \mathrm{mM} \beta$-glycerophosphate]. Forty micrograms of proteins was electrophoretically separated using sodium dodecyl sulfate-polyacrylamide gel electrophoresis on $8-15 \%$ gel and transferred to a polyvinylidene fluoride membrane. After blocking with TBS-T buffer [20 mM Tris ( $\mathrm{pH} 7.4$ ), $150 \mathrm{mM} \mathrm{NaCl}, 0.1 \%$ Tween-20] containing 5\% skim milk, the membranes were incubated with primary or secondary antibodies. The membranes were then washed with TBS-T buffer and visualized with enhanced chemiluminescence (ECL) western blot analysis detection reagents. The density of each band was determined using a fluorescence scanner (LAS 3000) and analyzed with Multi Gauge V3.0 software (both from Fuji Film, Tokyo, Japan).

Measurement of caspase-3 activity. For detection of caspase-3 activation, a caspase- 3 colorimetric assay kit (R\&D Systems 


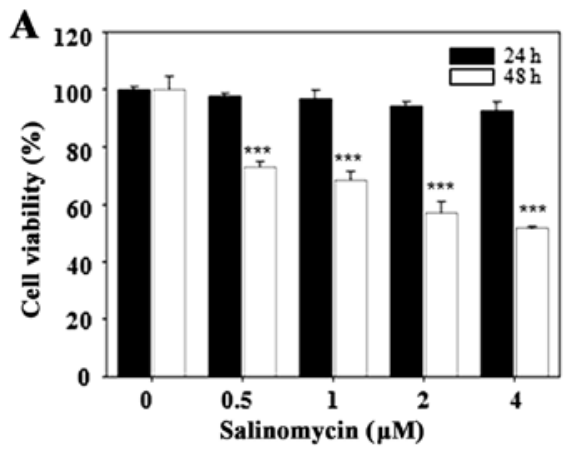

B

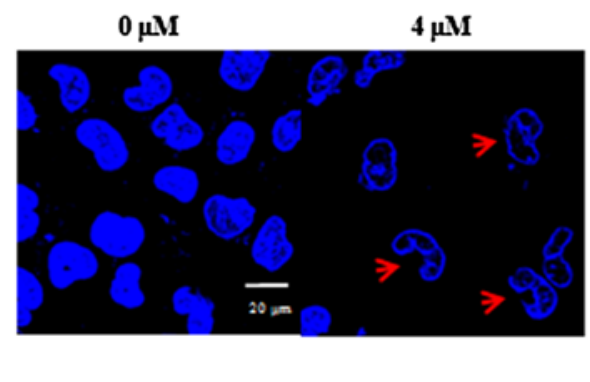

C

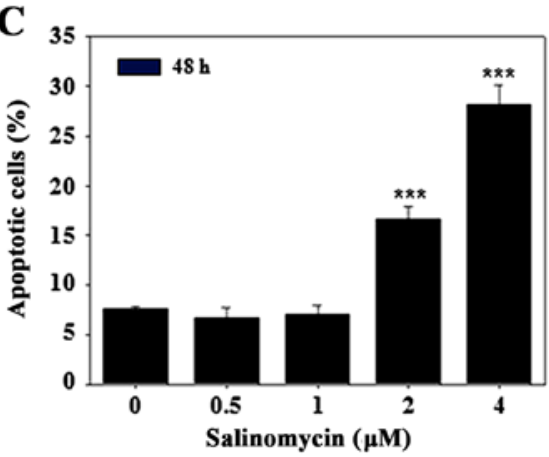

Figure 1. Salinomycin induces apoptosis. (A) Cell viability. U87MG cells were treated with the indicated doses of salinomycin for 24 or $48 \mathrm{~h}$. (B) Detection of morphological changes. U87MG cells were treated with $4 \mu \mathrm{M}$ salinomycin for $48 \mathrm{~h}$. Nuclear morphological changes were assessed using fluorescence microscopy after DAPI staining at room temperature for 10 min (magnification, $x 1,200)$. (C) Apoptosis analysis. Data are presented as mean \pm SD $(n=3$ in each group); ${ }^{* * *} \mathrm{p}<0.001$ vs. the untreated group.

$\mathbf{A}$

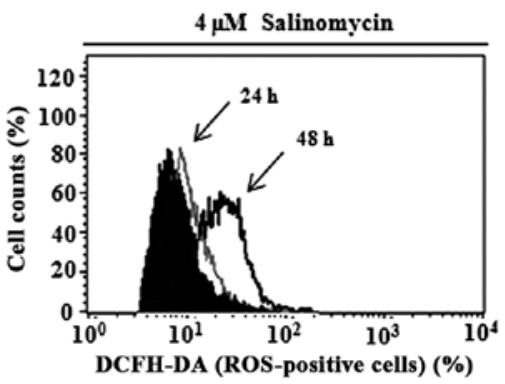

C

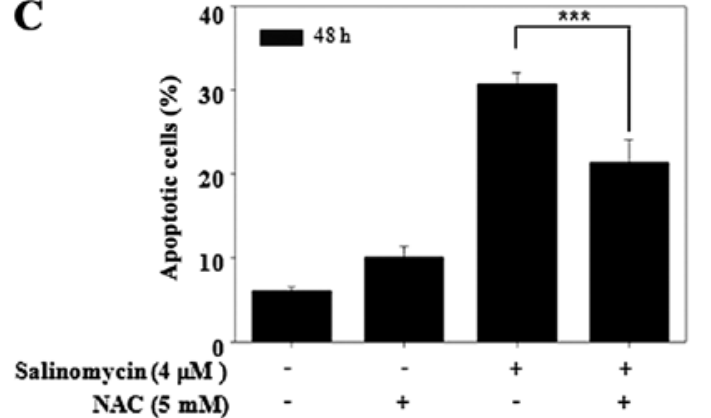

B

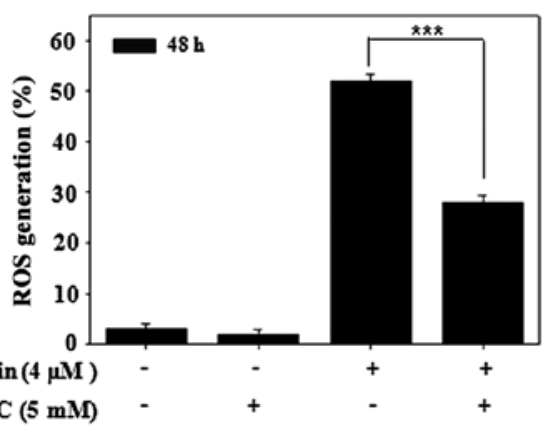

D

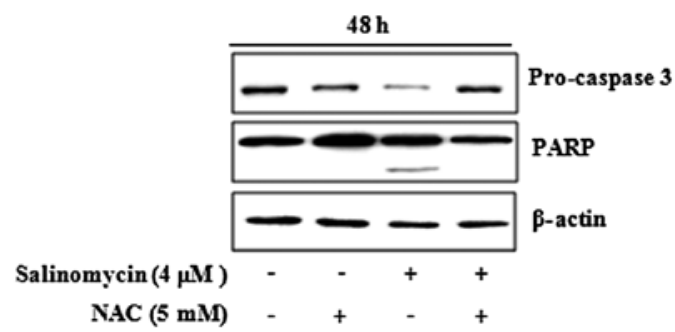

$\mathbf{E}$

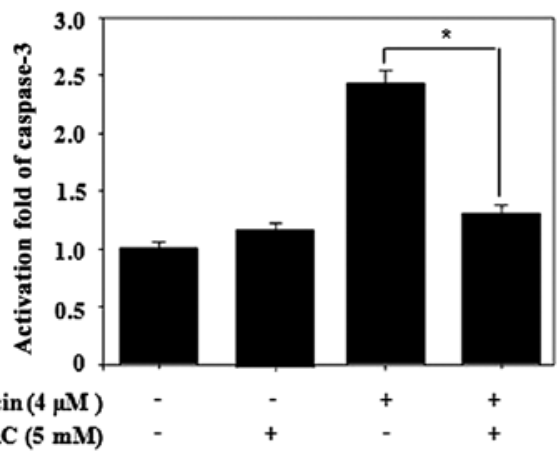

Figure 2. Salinomycin induces apoptosis via reactive oxygen species (ROS) in U87MG cells. (A) Levels of intracellular ROS. U87MG cells were treated with $4 \mu \mathrm{M}$ salinomycin for 24 or $48 \mathrm{~h}$. ROS were determined with fluorescence dye DCFH-DA by flow cytometry. (B) Levels of intracellular ROS. (C) Apoptosis analysis. (D) Expression of apoptosis-related proteins. (E) Caspase-3 activity. The U87MG cells were treated with $4 \mu \mathrm{M}$ salinomycin for $48 \mathrm{~h}$ with or without pre-treatment for $1 \mathrm{~h}$ with $5 \mathrm{mM} \mathrm{N}$-acety-1-cysteine (NAC). Caspase-3 activity was detected by caspase-3 colorimetric assay kit. Data are presented as mean $\pm \mathrm{SD}\left(\mathrm{n}=3\right.$ in each group); ${ }^{*} \mathrm{p}<0.05,{ }^{* * *} \mathrm{p}<0.001$ vs. the untreated group.

Inc., Minneapolis, MN, USA) was used according to the manufacturer's protocol. Equal amounts of protein $(220 \mu \mathrm{g})$ were resuspended in reaction buffer containing substrate
(Ac-DEVD-pNA), and then, incubated at $37^{\circ} \mathrm{C}$ for $4 \mathrm{~h}$ in the dark. The absorbance of the released pNA was measured at $405 \mathrm{~nm}$ using an ELISA reader. 
$\mathbf{A}$
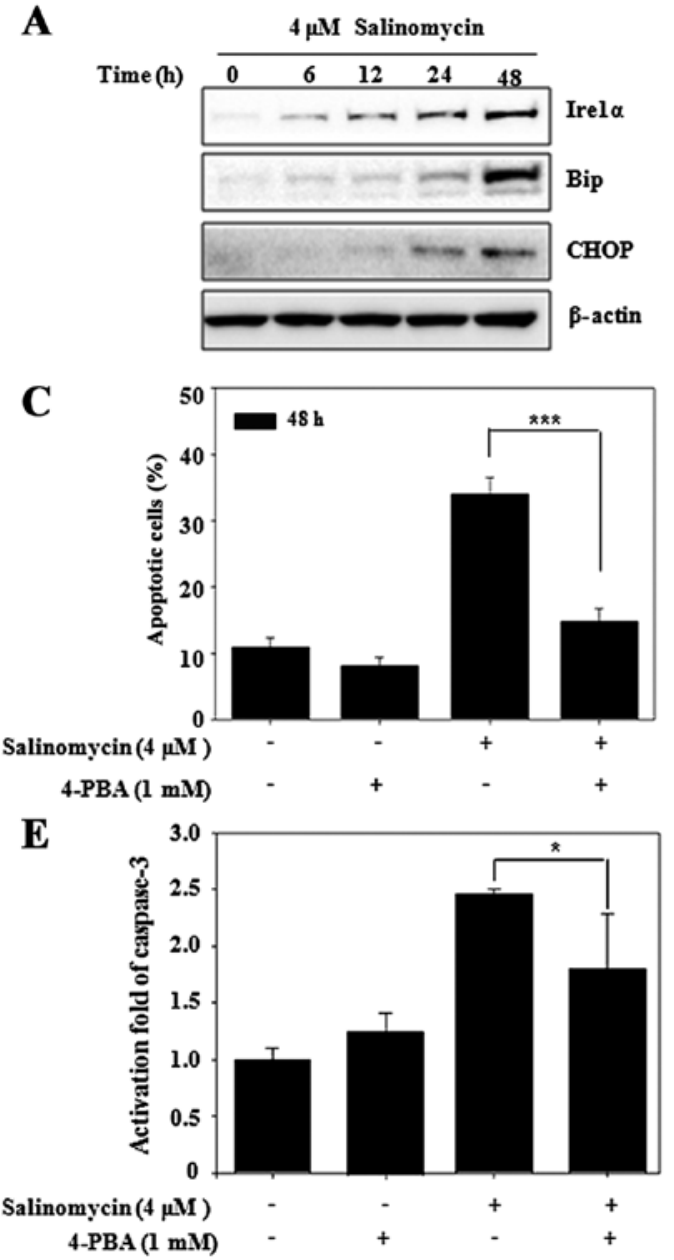

B

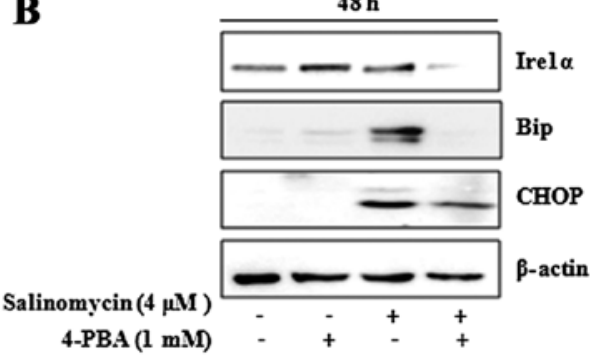

D

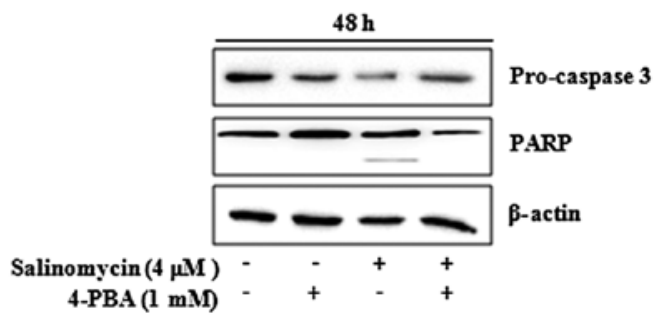

$\mathbf{F}$

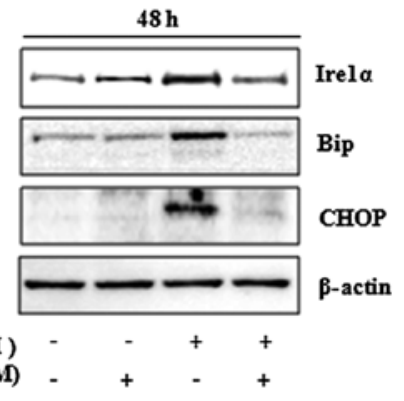

Figure 3. Salinomycin induces endoplasmic reticulum (ER) stress via ROS in U87MG cells. (A) Expression of ER stress-related proteins. U87MG cells were treated with salinomycin for the indicated times. (B) Expression of ER stress-related proteins. (C) Apoptosis analysis. (D) Expression of apoptosis-related proteins. (E) Caspase-3 activity. The U87MG cells were treated with $4 \mu \mathrm{M}$ salinomycin for $48 \mathrm{~h}$ with or without pre-treatment for $1 \mathrm{~h}$ with $2 \mathrm{mM} 4$-phenylbutyric acid (4-PBA). Caspase-3 activity was detected using the caspase-3 colorimetric assay kit. (F) Expression of ER stress-related proteins. The U87MG cells were treated with $4 \mu \mathrm{M}$ salinomycin for $48 \mathrm{~h}$ with or without pre-treatment for $1 \mathrm{~h}$ with $5 \mathrm{mM}$ NAC. Data are presented as mean $\pm \mathrm{SD}(\mathrm{n}=3 \mathrm{in}$ each group); $\mathrm{p}<0.05$, ${ }^{* * *} \mathrm{p}<0.001$ vs. the untreated group.

Statistical analysis. All experiments were repeated at least three times. Unless otherwise stated, data are expressed as the mean $\pm \mathrm{SD}$. Comparison of the experimental groups to the control values was carried out by ANOVA. Results were statistically significant at $\mathrm{p}<0.05$ or $\mathrm{p}<0.001 \mathrm{vs}$. the untreated group.

\section{Results}

Salinomycin induces apoptosis through generation of ROS in $U 87 M G$ cells. Salinomycin significantly decreased the cell viability of U87MG cells in a dose- and time-dependent manner (Fig. 1A). The 50\% inhibitory concentration after $48 \mathrm{~h}$ of treatment with salinomycin was $\sim 4 \mu \mathrm{M}$. Salinomycin caused a reduction in cell volume, nuclear condensation and an increase in non-adherent cells (Fig. 1B). In order to quantify salinomycin-induced apoptosis, Annexin V-PI double staining was performed. The percentage of apoptotic cells was increased in the salinomycin-treated cells, compared with the percentage in the control group (Fig. 1C). These results showed that salinomycin inhibited cell viability and induced apoptotic cell death in the U87MG cells.
Recent research has shown that anticancer drugs induce apoptosis, in part, by triggering ROS generation (4). To observe whether salinomycin produces ROS, the intracellular ROS level was determined with the fluorescent dye DCFH-DA. The ROS production was time-dependently increased after salinomycin treatment (Fig. 2A). However, the salinomycin-induced ROS production was reversed by the ROS scavenger NAC (Fig. 2B). Therefore, we observed whether the salinomycin-induced apoptosis is associated with ROS production. Pre-treatment with NAC recovered salinomycin-induced apoptosis (Fig. 2C) and rescued expression of apoptosis-related proteins, such as pro-caspase-3 and PARP (Fig. 2D). Furthermore, consistent with western blot analysis, salinomycin-induced caspase-3 activation was reversed by NAC (Fig. 2E). Taken together, ROS induced by salinomycin regulated apoptotic cell death in the U87MG cells.

Salinomycin induces ER stress-mediated apoptosis in U87MG cells. The misfolded proteins induced ER stress to restore protein homeostasis and apoptotic cell death ensues when the stress is prolonged. Recent research revealed that apoptosis is induced 
$\mathbf{A}$

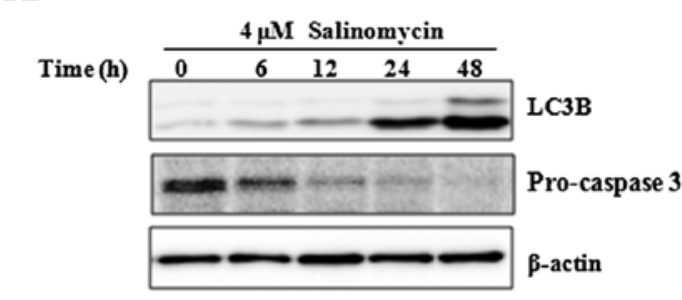

C

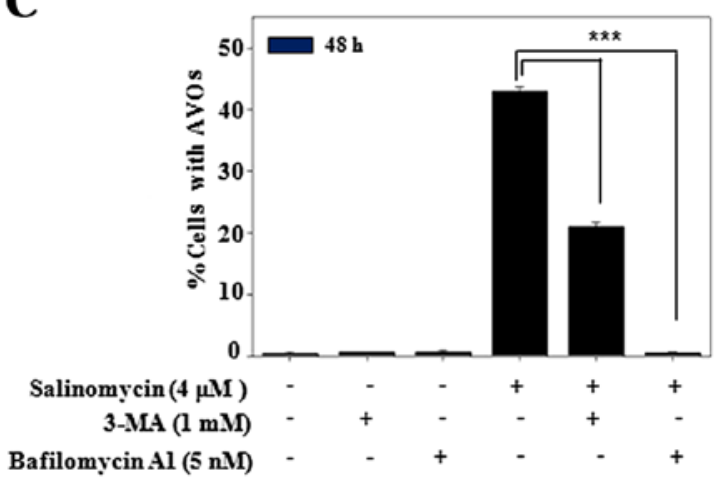

$\mathbf{E}$

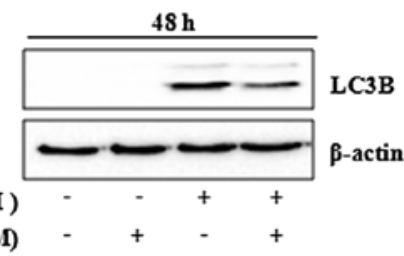

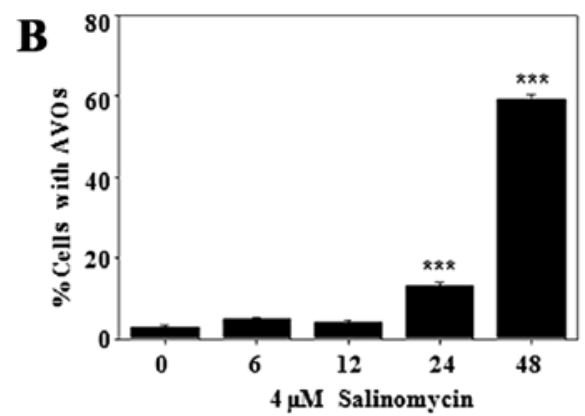

D
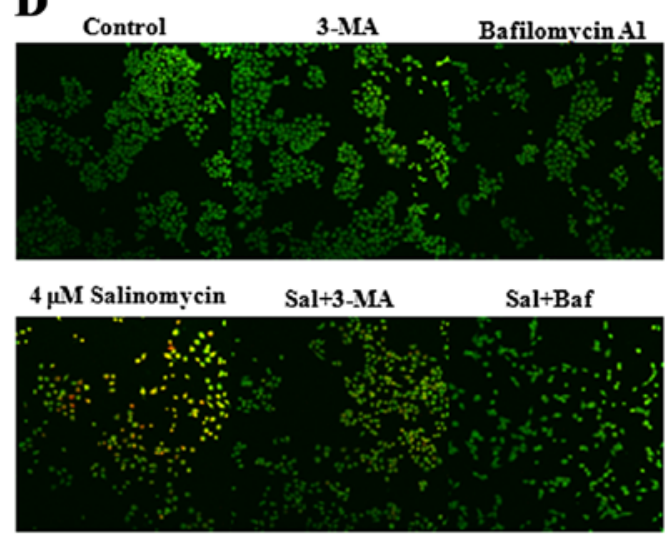

$\mathbf{F}$

$48 \mathrm{~h}$

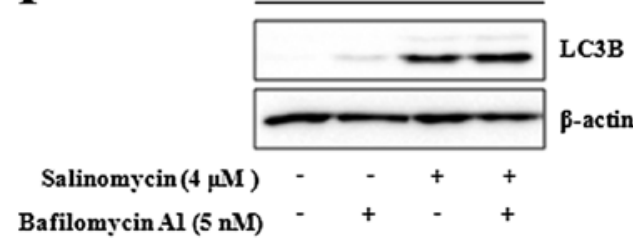

Figure 4. Salinomycin induces autophagy in U87MG cells. (A) Expression of LC3B and caspase-3 protein. (B) Detection of acidic vesicular organelles (AVOs). U87MG cells were treated with salinomycin for the indicated times. (C) Detection of AVOs. (D) Detection of morphological changes. Acridin orange-stained cells were measured using fluorescence microscopy (magnification, $\mathrm{x} 1,200$ ). (E and F) Expression of LC3B protein. U87MG cells were treated with $4 \mu \mathrm{M}$ salinomycin for $48 \mathrm{~h}$ with or without pre-treatment for $1 \mathrm{~h}$ with $1 \mathrm{mM} 3$-methyladenine (3-MA) or $5 \mathrm{nM}$ bafilomycin A1. Data are presented as mean \pm SD ( $=3$ in each group); ${ }^{* * * *} \mathrm{p}<0.001 \mathrm{vs}$. the untreated group.

via stimulation of ER stress in glioma cells $(6,21)$. To investigate the ER stress pathway involved in salinomycin-induced apoptosis, we examined the expression levels of ER stress-related proteins (Ire1 $\alpha$, Bip and CHOP) by western blot analysis. Salinomycin increased the expression of Ire1 $\alpha$, Bip and CHOP in a time-dependent manner (Fig. 3A). However, addition of the ER stress inhibitor, 4-PBA, resulted in suppression of these proteins (Fig. 3B). We observed the relationship between ER stress and apoptosis using 4-PBA. As shown in Fig. 3C, salinomycin-induced apoptosis was also significantly blocked by 4-PBA, which was confirmed by suppression of the activation of caspase-3 and expression of PARP (Fig. 3D and E). In addition, we observed the relationship between ROS production and ER stress responses in regards to apoptosis. As shown in Fig. 3F, ER stress-related proteins were also suppressed by NAC. These results indicated that ER stress plays a crucial role in the upstream pathway of salinomycin-induced apoptosis and is regulated by ROS generation in U87MG cells.

Salinomycin induces ER stress-mediated autophagy in U87MG cells. Programmed cell death (apoptosis) is mainly regulated by the autophagy pathway (22). However, autophagy can independently act upon apoptotic signaling pathways, thus we determined the autophagy level after salinomycin treatment in the U87MG cells. Increased expression of autophagy marker protein LC3B and apoptosis marker caspase-3 were observed in a time-dependent manner (Fig. 4A). The formation of acidic vesicular organelles (AVOs), autophagy-related lysosomal structures, was also increased, as determined using vital staining with acridine orange (23) (Fig. 4B). However, the formation of AVOs was suppressed by pre-treatment with 3-MA, an inhibitor of autophagosome formation or bafilomycin A1, an inhibitor of lysosome formation (Fig. 4C). These results indicated that salinomycin induced autophagic flux in the U87MG cells, as confirmed by acridin orange-stained cells with co-treatment of 3-MA or bafilomycin Al (Fig. 4D). As shown in Fig. 4E, salinomycin also increased autophagic marker protein LC3B, which was blocked in the presence of 3-MA. However, addition of the lysosome inhibitor bafilomycin A1 resulted in further accumulation of LC3B as compared to cells treated with the single agent (Fig. 4F). These results indicated that salinomycin induced autophagic flux in the U87MG cells, which was recovered by co-treatment of 3-MA and enhanced with bafilomycin A1. 
$\mathbf{A}$

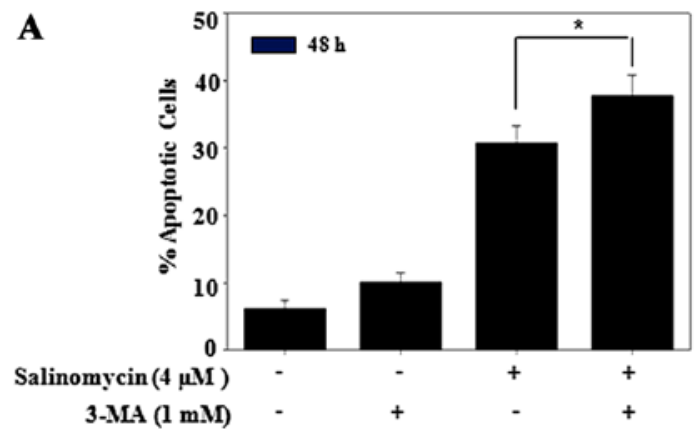

C

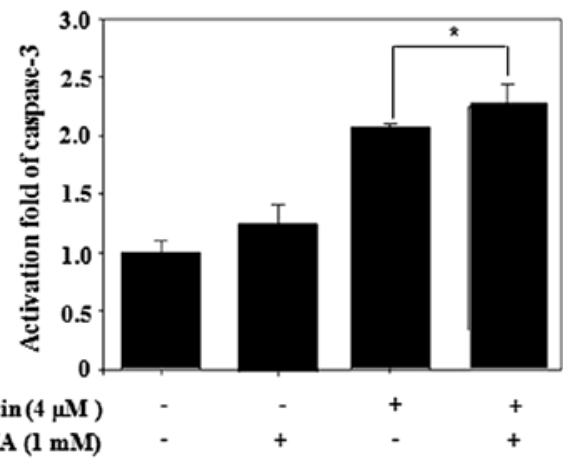

$\mathbf{E}$

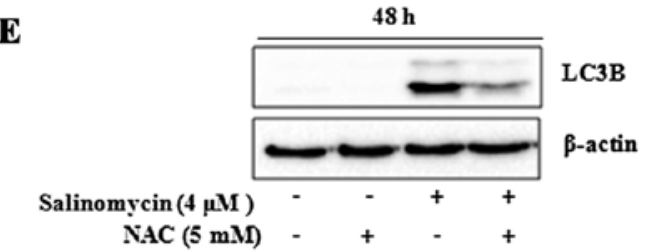

G

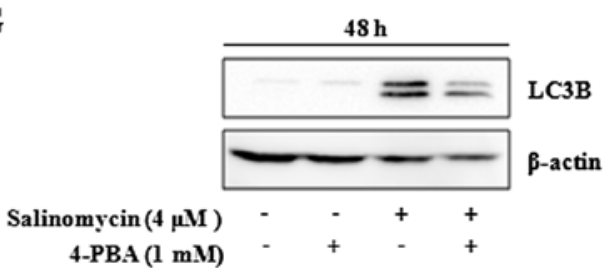

B

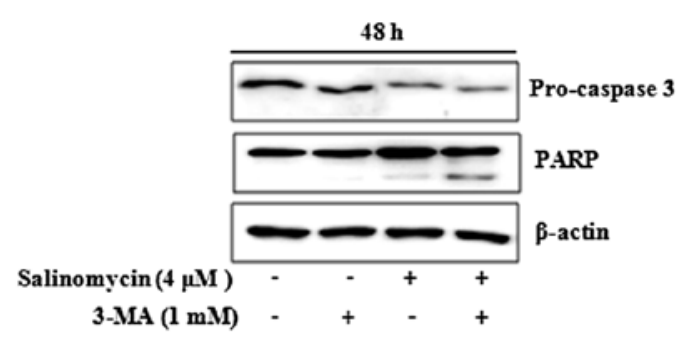

D

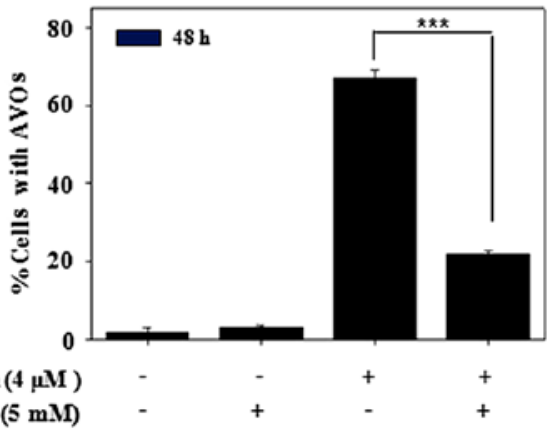

$\mathbf{F}$

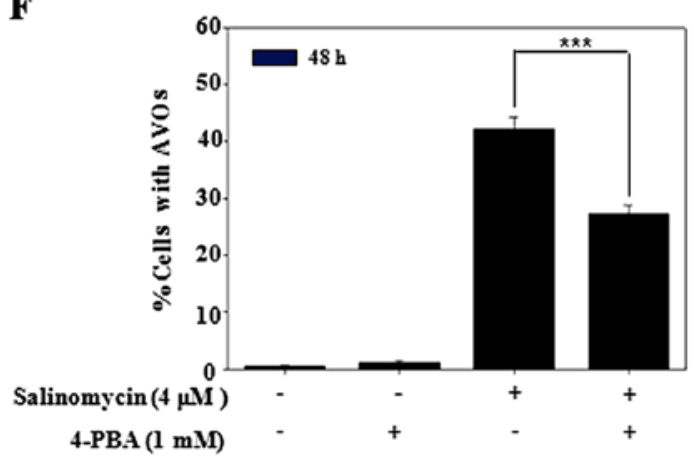

Figure 5. Salinomycin regulates apoptosis by autophagy in U87MG cells. (A) Apoptosis analysis. (B) Expression of apoptosis-related proteins. (C) Caspase-3 activity. U87MG cells were treated with salinomycin for $48 \mathrm{~h}$ with or without pre-treatment for $1 \mathrm{~h}$ with $1 \mathrm{mM} 3-\mathrm{MA}$. Caspase-3 activity was detected using the caspase-3 colorimetric assay kit. (D) Detection of acidic vesicular organelles (AVOs). (E) Expression of LC3B protein. (F) Detection of AVOs. (G) Expression of LC3B protein. U87MG cells were treated with $4 \mu \mathrm{M}$ salinomycin for $48 \mathrm{~h}$ with or without pre-treatment for $1 \mathrm{~h}$ with $5 \mathrm{mM} \mathrm{NAC}$ or $1 \mathrm{mM} 4$-phenylbutyric acid (4-PBA). Data are presented as mean $\pm \mathrm{SD}\left(\mathrm{n}=3\right.$ in each group); ${ }^{*} \mathrm{p}<0.05,{ }^{* * *} \mathrm{p}<0.001 \mathrm{vs}$. the untreated group.

Salinomycin regulates apoptosis through autophagyin U87MG cells. To address the role of autophagy against salinomycininduced apoptosis, the percentage of apoptotic cells and expression of apoptosis-related proteins were determined. Pre-treatment with 3-MA enhanced the salinomycin-induced apoptosis (Fig. 5A), resulting from reduced pro-caspase-3 and accumulation of cleaved PARP in the U87MG cells (Fig. 5B). Furthermore, salinomycin induced caspase- 3 activation enhanced by 3-MA (Fig. 5C). In addition, we also observed that the formation of AVOs and expression of LC3B were suppressed by the pre-treatment of NAC (Fig. 5D and E), which indicated the regulation of autophagy by ROS. Next, to observe the relationship between ER stress and autophagy, 4-PBA as an ER stress inhibitor was applied. As shown in Fig. 5F, the formation of AVOs was significantly blocked by 4-PBA, leading to recovered expression of LC3B (Fig. 5G).
These results demonstrated that autophagy flux caused a delay in salinomycin-induced apoptosis in the U87MG cells, which was regulated by ER stress responses mediated from upstream ROS.

\section{Discussion}

Autophagy is an intracellular metabolic system in eukaryotic cells, in which autophagosomes fuse with lysosomes and degrade intracellular materials to maintain cell homeostasis (24). It function in a protective role from drug-induced cell death (25). Autophagy inhibits apoptosis by promoting cell survival or induces cell death by cooperating with apoptosis signaling (26). Apoptosis and autophagy are interrelated and undergo crosstalk. Due to its pro-survival function, autophagy makes cancer cells resistant to chemotherapy, radiotherapy 


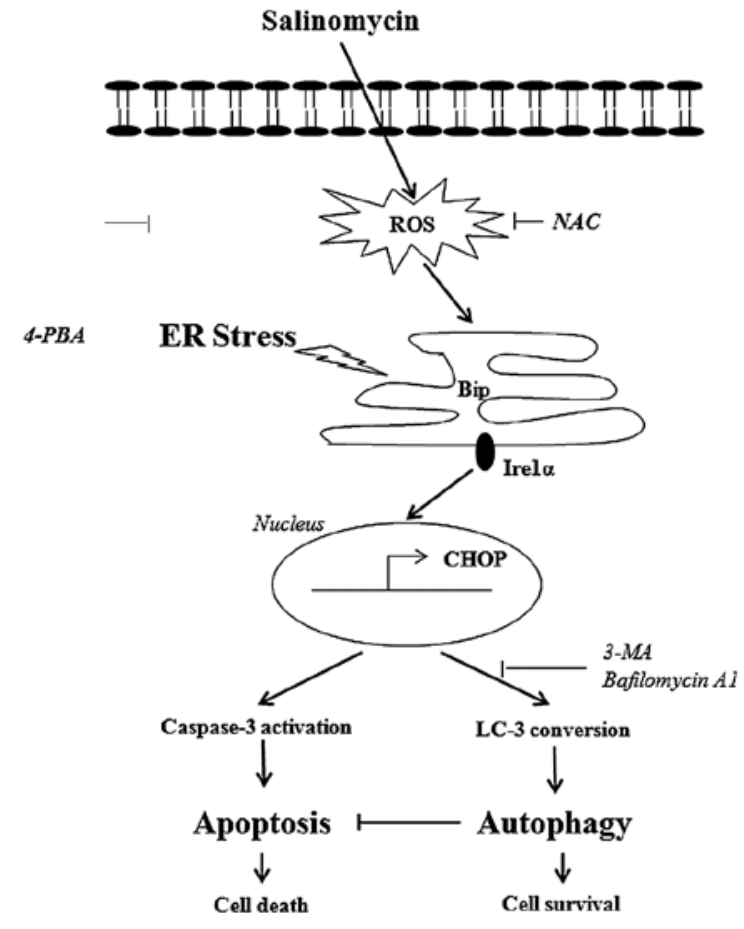

Figure 6. Schematic drawing representing the possible mechanisms involved in the endoplasmic reticulum (ER) stress-mediated autophagy and apoptosis by salinomycin. ROS, reactive oxygen species; NAC, N-acety-1-cysteine.

or anti-angiogenic therapy. It is tightly regulated by several conserved autophagy proteins. Inhibition of autophagy has been widely recognized to improve the efficacy of anticancer agents (27). Anticancer compounds may affect cellular redox reactions through accumulation of intracellular ROS $(28,29)$, which in turn induce apoptosis and autophagy (30). Accumulating evidence indicates that apoptosis is also regulated by ER stress $(6,21)$. ER is a key organelle with protein processing, intracellular calcium storage, as well as signaling regulation functions in eukaryotic cells (31).

Although the anticancer effects of salinomycin have been established in a variety of preclinical studies using many different cancer types, there are few studies on the effects of salinomycin on glioma cancer cells (6). In the present study, salinomycin showed potent cytotoxic and apoptotic effects in human glioma U87MG cells. We found that the level of intracellular ROS was increased after salinomycin treatment and antioxidant NAC rescued the apoptosis level. In addition, salinomycin stimulated the expression of ER stress-related proteins, including Ire1 $\alpha$, Bip and CHOP. Indeed, salinomycin-induced apoptosis was suppressed by ER stress inhibitor, 4-PBA, in the U87MG cells. These results suggest that apoptosis may be regulated via ER stress signaling. Moreover, NAC suppressed the expression of Ire1 $\alpha$, Bip, CHOP and LC3B and the formation of AVOs. Therefore, salinomycin induced ER stress and autophagy by promoting ROS generation, resulting in cellular apoptosis. In addition, salinomycin induced an increased autophagic level by causing increased expression of LC3B and accumulation of AVOs in the U87MG cells. These phenomena were recovered by autophagy inhibitor 3-MA, which resulted in increased apoptosis. In addition, suppression of ER stress using 4-PBA inhibited the salinomycin-induced autophagy, as confirmed by reduction in $\mathrm{LC} 3 \mathrm{~B}$ and $\mathrm{AVO}$ formation. This indicated that autophagy was regulated through the ER stress responses induced by salinomycin.

In conclusion, we demonstrated that salinomycin induced apoptosis through the ROS-mediated ER stress signaling pathway, which was protected by ER stress-mediated autophagy (Fig. 6). As salinomycin has the potential as a chemotherapeutic agent for human glioma cancer cells, future pre-clinical studies are warranted to confirm its usefulness as a clinical drug candidate for glioma cancer treatment. In addition, blocking of ER stress responses could be a useful strategy to target cancer cell resistance to chemotherapies.

\section{Acknowledgements}

The present study was supported by the 2012 Specialization Project Research Grant funded by the Pusan National University.

\section{References}

1. Dong TT, Zhou HM, Wang LL, Feng B, Lv B and Zheng MH: Salinomycin selectively targets ' $\mathrm{CD} 133^{+}$' cell subpopulations and decreases malignant traits in colorectal cancer lines. Ann Surg Oncol 18: 1797-1804, 2011.

2. Wang F, He L, Dai WQ, Xu YP, Wu D, Lin CL, Wu SM, Cheng P, Zhang Y, Shen M, et al: Salinomycin inhibits proliferation and induces apoptosis of human hepatocellular carcinoma cells in vitro and in vivo. PLoS One 7: e50638, 2012.

3. Kusunoki S, Kato K, Tabu K, Inagaki T, Okabe H, Kaneda H, Suga S, Terao Y, Taga T and Takeda S: The inhibitory effect of salinomycin on the proliferation, migration and invasion of human endometrial cancer stem-like cells. Gynecol Oncol 129: 598-605, 2013.

4. Kim KY, Yu SN, Lee SY, Chun SS, Choi YL, Park YM, Song CS, Chatterjee B and Ahn SC: Salinomycin-induced apoptosis of human prostate cancer cells due to accumulated reactive oxygen species and mitochondrial membrane depolarization. Biochem Biophys Res Commun 413: 80-86, 2011.

5. Kim SH, Choi YJ, Kim KY, Yu SN, Seo YK, Chun SS, Noh KT, Suh JT and Ahn SC: Salinomycin simultaneously induces apoptosis and autophagy through generation of reactive oxygen species in osteosarcoma U2OS cells. Biochem Biophys Res Commun 473: 607-613, 2016.

6. Xipell E, Gonzalez-Huarriz M, Martinez de Irujo JJ, GarcíaGarzón A, Lang FF, Jiang H, Fueyo J, Gomez-Manzano C and Alonso MM: Salinomycin induced ROS results in abortive autophagy and leads to regulated necrosis in glioblastoma. Oncotarget 7: 30626-30641, 2016.

7. Chu SH, Feng DF, Ma YB, Zhang H, Zhu ZA, Li ZQ and Jiang PC: Promoter methylation and downregulation of SLC22A18 are associated with the development and progression of human glioma. J Transl Med 9: 156, 2011.

8. Wei KC, Huang CY, Chen PY, Feng LY, Wu TW, Chen SM, Tsai HC, Lu YJ, Tsang NM, Tseng CK, et al: Evaluation of the prognostic value of CD44 in glioblastoma multiforme. Anticancer Res 30: 253-259, 2010.

9. Ohgaki $\mathrm{H}$ and Kleihues P: Epidemiology and etiology of gliomas. Acta Neuropathol 109: 93-108, 2005.

10. Das A, Banik NL and Ray SK: $N$-(4-Hydroxyphenyl) retinamide induced both differentiation and apoptosis in human glioblastoma T98G and U87MG cells. Brain Res 1227: 207-215, 2008.

11. Powis G, Gasdaska JR, Gasdaska PY, Berggren M, Kirkpatrick DL, Engman L, Cotgreave IA, Angulo M and Baker A: Selenium and the thioredoxin redox system: Effects on cell growth and death. Oncol Res 9: 303-312, 1997.

12. Sun Y and Rigas B: The thioredoxin system mediates redoxinduced cell death in human colon cancer cells: Implications for the mechanism of action of anticancer agents. Cancer Res 68: 8269-8277, 2008. 
13. Simon HU, Haj-Yehia A and Levi-Schaffer F: Role of reactive oxygen species (ROS) in apoptosis induction. Apoptosis 5: 415-418, 2000

14. Rigoulet M, Yoboue ED and Devin A: Mitochondrial ROS generation and its regulation: Mechanisms involved in $\mathrm{H}_{2} \mathrm{O}_{2}$ signaling. Antioxid Redox Signal 14: 459-468, 2011.

15. Jang JH, Kim YJ, Kim H, Kim SC and Cho JH: Buforin IIb induces endoplasmic reticulum stress-mediated apoptosis in HeLa cells. Peptides 69: 144-149, 2015.

16. Ron D and Hubbard SR: How IRE1 reacts to ER stress. Cell 132: 24-26, 2008.

17. Kouroku Y, Fujita E, Tanida I, Ueno T, Isoai A, Kumagai H, Ogawa S, Kaufman RJ, Kominami E and Momoi T: ER stress (PERK/eIF2alpha phosphorylation) mediates the polyglutamineinduced LC3 conversion, an essential step for autophagy formation. Cell Death Differ 14: 230-239, 2007.

18. Szegezdi E, Logue SE, Gorman AM and Samali A: Mediators of endoplasmic reticulum stress-induced apoptosis. EMBO Rep 7: 880-885, 2006

19. White E and DiPaola RS: The double-edged sword of autophagy modulation in cancer. Clin Cancer Res 15: 5308-5316, 2009.

20. Amaravadi RK, Yu D, Lum JJ, Bui T, Christophorou MA, Evan GI, Thomas-Tikhonenko A and Thompson CB: Autophagy inhibition enhances therapy-induced apoptosis in a Myc-induced model of lymphoma. J Clin Invest 117: 326-336, 2007.

21. Yoon MJ, Kang YJ, Kim IY, Kim EH, Lee JA, Lim JH, Kwon TK and Choi KS: Monensin, a polyether ionophore antibiotic, overcomes TRAIL resistance in glioma cells via endoplasmic reticulum stress, DR5 upregulation and c-FLIP downregulation. Carcinogenesis 34: 1918-1928, 2013.
22. Lockshin RA and Zakeri Z: Apoptosis, autophagy, and more. Int J Biochem Cell Biol 36: 2405-2419, 2004.

23. Paglin S, Hollister T, Delohery T, Hackett N, McMahill M, Sphicas E, Domingo D and Yahalom J: A novel response of cancer cells to radiation involves autophagy and formation of acidic vesicles. Cancer Res 61: 439-444, 2001.

24. Liu M, Ma S, Liu M, Hou Y, Liang B, Su X and Liu X: Synergistic killing of lung cancer cells by cisplatin and radiation via autophagy and apoptosis. Oncol Lett 7: 1903-1910, 2014.

25. Malhi H, Gores GJ and Lemasters JJ: Apoptosis and necrosis in the liver: A tale of two deaths? Hepatology 43 (Suppl 1): S31-S44, 2006.

26. Eisenberg-Lerner A, Bialik S, Simon HU and Kimchi A: Life and death partners: Apoptosis, autophagy and the cross-talk between them. Cell Death Differ 16: 966-975, 2009.

27. Maycotte P and Thorburn A: Autophagy and cancer therapy. Cancer Biol Ther 11: 127-137, 2011.

28. Delaunay-Moisan A and Appenzeller-Herzog C: The antioxidant machinery of the endoplasmic reticulum: Protection and signaling. Free Radic Biol Med 83: 341-351, 2015.

29. Cheng Z and Ristow M: Mitochondria and metabolic homeostasis. Antioxid Redox Signal 19: 240-242, 2013.

30. Wang CL, Liu C, Niu LL, Wang LR, Hou LH and Cao XH: Surfactin-induced apoptosis through ROS-ERS-Ca ${ }^{2+}$-ERK pathways in HepG2 cells. Cell Biochem Biophys 67: 1433-1439, 2013.

31. Moir RD, Gross DA, Silver DL and Willis IM: SCS3 and YFT2 link transcription of phospholipid biosynthetic genes to ER stress and the UPR. PLoS Genet 8: e1002890, 2012. 